\title{
Análisis bromatológico y producción de gas in vitro de forrajes utilizados en el trópico seco mexicano
}

Almaraz-Buendía, I. ' ; García, A.M. ${ }^{2}$; Sánchez-Santillán, P. ${ }^{3}$; Torres-Salado, N. ${ }^{3}$; Herrera-Pérez, J. ${ }^{3}$; Bottini-Luzardo, M.B. ${ }^{3}$ Y Rojas-García, A.R. ${ }^{3}$

Instituto de Ciencias Agropecuarias, Universidad Autónoma del Estado de Hidalgo. Tulancingo, Hidalgo, México.

2Licenciatura de Médico Veterinario Zootecnista de la Universidad Autónoma de Guerrero, Cuajinicuilapa, Guerrero. México.

${ }^{3}$ Facultad de Medicina Veterinaria y Zootecnia No. 2, Universidad Autónoma de Guerrero. Cuajinicuilapa, Guerrero. México.

PALABRAS CLAVE ADICIONALES

Metano.

Composición química.

Cinética de fermentación.

Degradación.

Pastos tropicales.

\section{ADDITIONAL KEYWORDS}

Methane.

Chemical composition.

Fermentation kinetics.

Degradation.

Tropical pastures.

\section{INFORMATION}

Cronología del artículo.

Recibido/Received: 05.07 .2018

Aceptado/Accepted: 24.03.2019

On-line: 07.04 .2019

Correspondencia a los autores/Contact e-mail:

sanchezsantillanp@gmail.com

\section{RESUMEN}

La calidad de los pastos tropicales se relaciona con su uso en la producción de rumiantes, ya que estos basan su alimentación en su consumo. El objetivo fue determinar el análisis bromatológico, producción de gas in vitro y características fermentativas de nueve pastos utilizados en la alimentación de rumiantes en el trópico seco mexicano. Los pastos fueron bermuda, mulato, insurgente, estrella, bramilla, llanero, mombaza, pará y pangola a 56 d de rebrote. En los pastos se determinó proteína bruta (PB), cenizas (Ce), fibra neutro detergente (FND), fibra ácido detergente (FAD), cinética de fermentación, producción de gases, ácidos grasos volátiles (AGV), conteo de bacterias totales, degradaciones de materia seca (DEGMS), fibra neutro detergente (DEGFND) y fibra ácida detergente (DEGFAD). La PB fue mayor en mombaza y pará. La FND fue menor en llanero, mombaza, mulato y pangola. La Ce fue menor en estrella y llanero $(P<0,05)$. La FAD no mostró diferencias entre pastos $(\mathrm{P}>0,05)$. La producción de metano $\left(\mathrm{CH}_{4}\right)$ fue mayor en bramilla, llanero, mombaza y pangola a las $24 \mathrm{~h}$, bermuda mayor a las $48 \mathrm{~h}$ y estrella, insurgente y pangola a las $72 \mathrm{~h}(\mathrm{P}<0,05)$. La producción de gas total fue mayor para mombaza. La DEGMS fue mayor en mombaza y mulato. La DEGFND fue mayor en mombaza y la DEGFAD fue mayor en bermuda, insurgente, mombaza y mulato $(\mathrm{P}<0,05)$. El conteo de bacterias fue mayor en bramilla, estrella, pará y mombaza $(P<0,05)$. Los pastos no mostraron diferencias en acetato, butirato y $A G V$ totales $(P>0,05)$. Se concluye, el pasto mombaza obtuvo las mejores características bromatológicas, las mejores producciones de gas total, donde el metano representó $40,3 \%$ y las mayores degradaciones de las fibras detergentes neutra y ácida.

\section{Bromatological analysis and in vitro gas production of forages used in dry mexican tropic}

\section{SUMMARY}

The quality of tropical pastures is related to their use in the production of ruminants, since they base their diet on their consumption. The objective was to determine the bromatological analysis, in vitro gas production and fermentative characteristics of nine kinds of grass used in the feeding of ruminants in the dry Mexican tropics. The pastures were bermuda, mulato, insurgent, star, bramilla, llanero, mombaza, para and pangola to $56 \mathrm{~d}$ of regrowth. In the pastures it was determined crude protein (CP), ash (As), neutral detergent fiber (NDF), acid detergent fiber (ADF), fermentation kinetics, gas production, volatile fatty acids (VFA), total bacteria count, dry matter degradations (DMDEG), neutral detergent fiber degradations (NDFDEG) and acid detergent fiber degradations (ADFDEG). CP was higher in mombaza and para. The NDF was lower in llanero, mombaza, mulato and pangola. The As was lower in star and llanero $(P<0.05)$. The ADF showed no differences between pastures $(P>0.05)$. The production of methane $\left(\mathrm{CH}_{4}\right)$ was higher in bramilla, llanero, mombaza and pangola at $24 \mathrm{~h}$, bermuda was higher at $48 \mathrm{~h}$ and star, insurgent and pangola was higher at $72 \mathrm{~h}(\mathrm{P}<0.05)$. The total gas production was higher for mombaza. The DMDEG was higher in mombaza and mulato. The NDFDEG was higher in mombaza and the ADFDEG was higher in bermuda, insurgent, mombaza and mulato $(P<0,05)$. The bacteria count was higher in bramilla, star, pará and mombaza $(\mathrm{P}<0.05)$. Pastures did not show difference in acetate, butyrate and total VFA ( $P>0.05)$. It is concluded, that the mombaza grass obtained the best bromatological characteristics, the best total gas production, where methane represented $40.3 \%$ and the higher degradations of the neutral and acid detergent fibers.

\section{INTRODUCCIÓN}

La calidad de los pastos se relaciona directamente con su uso en la producción de rumiantes para la ob- tención de carne y leche (Muñoz-González et al. 2016, p. 3316); ya que, los rumiantes en el trópico basan su alimentación en forrajes por su alta producción de bio- 
masa (Ortega-Aguirre et al. 2015, p. 292). Dado que en el trópico se encuentran aproximadamente $31,5 \%$ de la producción bovina nacional, 14,0 \% de la producción ovina nacional y 13,4 \% de la producción caprina nacional (Román 1981, p. 394). Los forrajes se diferencian en la estructura, composición de su pared celular, especie vegetal, parte anatómica y fase de la pared celular (Muñoz-González et al. 2016, p. 3316). La pared celular de los tejidos vegetales contiene de 35 a $80 \%$ de la materia orgánica, la cual proporciona rigidez estructural a la planta. Los factores determinantes de la composición química de los forrajes son factores propios de la planta (especie, edad, morfología, etc.) y factores ambientales (temperatura, radiación solar, precipitación, fertilidad y tipo de suelo) (Castro-Hernández et al. 2017, p. 202). El rendimiento, la composición botánica y calidad del forraje también se afectan por la intensidad, la frecuencia y la oportunidad de uso (Faría 2006, pp. 1-2). El crecimiento de una planta involucra un ensanchamiento de la célula mediante la síntesis de una pared celular secundaria que afecta la digestibilidad de la planta (Ramírez 2002, pp. 180-181); ya que el tipo de carbohidratos influye en la digestibilidad y en el consumo (Valenciaga \& Chongo 2004, p. 347).

El consumo de forrajes con alta concentración de pared celular muestra baja digestibilidad y disponibilidad de energía. El consumo de gramíneas tropicales por rumiantes genera una subutilización de carbohidratos estructurales, lo que impide el uso óptimo de los nutrientes presentes en los forrajes (Posada \& Noguera 2005, p. 1-2; Sánchez et al. 2005, p. 58; Valenciaga \& Chongo 2004, pp. 347-349). Lo anterior demanda la evaluación nutrimental de los forrajes tropicales, como análisis bromatológico, pruebas de producción de gas in vitro, pruebas in situ e in vivo para formular dietas o complementos desde el punto de vista fisiológico y económico que optimice la productividad animal (Sánchez et al. 2005, p. 58). Por tanto, el objetivo fue determinar la composición química, la cinética de producción de gas, producción de gas in vitro y características fermentativas de los principales forrajes usados para la alimentación de rumiantes del trópico seco mexicano para comparar el potencial nutricional mediante la técnica de producción de gas in vitro.

\section{MATERIAL Y MÉTODOS}

\section{LOCALIZACIÓN DEL ESTUDIO}

La investigación se hizo en el laboratorio de $\mathrm{Nu}$ trición Animal de la Facultad de Medicina Veterinaria y Zootecnia No. 2 del municipio de Cuajinicuilapa, Guerrero, México. El municipio se sitúa entre las coordenadas $16^{\circ} 18^{\prime}$ y $16^{\circ} 36^{\prime}$ latitud norte y $98^{\circ} 23^{\prime}$ y $98^{\circ}$ $40^{\prime}$ longitud oeste a $50 \mathrm{msnm}$.

\section{Muestras}

Las muestras fueron los pastos bermuda (Cynodon dactylon), mulato (Brachiaria híbrida), insurgente (Brachiaria brizantha), estrella (Cynodon nlemfuensis), bramilla (Elytrichia repens), llanero (Andropogon gayanus), mombaza (Panicum maximun), pará (Brachiaria mutica) y pangola (Digitaria decumbens). Los pastos se recolectaron a los 56 días de rebrote y se desecaron a 60
${ }^{\circ} \mathrm{C}$ durante $48 \mathrm{~h}$ en estufa (RIOSSA ${ }^{\circledR} \mathrm{HCF}-41$, México) de ventilación natural y se molieron a tamaño de $1 \mathrm{~mm}$ en un molino Thomas-Wiley Mill (Thomas Scientific ${ }^{\circledR}$, Swedesboro, NJ, USA).

\section{ANÁLISIS BROMATOLÓGICO}

En cada pasto se analizó por triplicado el contenido de proteína bruta (PB) y cenizas (Ce) con los métodos descritos por la AOAC (2005). Las fibras neutro detergente (FND) y ácido detergente (FAD), según Van Soest et al. (1991, pp. 3584-3586).

\section{Medio de Cultivo.}

El medio de cultivo se compuso de dos tercios de una solución buffer-mineral reducida y un tercio de fluido ruminal fresco. El fluido ruminal fresco se obtuvo de un bovino provisto de cánula ruminal alimentado previamente en praderas con pasto pangola (Digitaria decumbes) y se filtró con una manta de cielo para eliminar macropartículas. El uso de pasto pangola para la alimentación del bovino donador de fluido ruminal es porque este pasto ocupa la mayor superficie en el trópico seco. El bovino se manejó de acuerdo al reglamento interno de bioética y bienestar de la UAGro con fundamento en las normas oficiales (NOM-062ZOO-1999 y NOM-051-ZOO-1995). La solución buffermineral reducida fue según Hernández-Morales et al. (2018, p. 109) y Torres-Salado et al. (2018, p. 56).

\section{BIODIGESTORES.}

En un vial serológico $(120 \mathrm{~mL})$ se agregaron $0,5 \mathrm{~g}$ de muestra seca y $50 \mathrm{~mL}$ de medio de cultivo, bajo flujo continuo de $\mathrm{CO}_{2}$, para mantener condiciones de anaerobiosis. Los viales se sellaron con un tapón de neopreno y un arillo de aluminio con centro removible. Los biodigestores se incubaron en baño maría a $39^{\circ} \mathrm{C}$ por $72 \mathrm{~h}$

\section{PRODUCCIÓN DE GAS TOTAL Y CINÉTICA DE PRODUCCIÓN DE GAS IN VITRO}

La producción de gas in vitro (5 determinaciones independientes por muestra de forraje) se midió mediante el desplazamiento del embolo de una jeringa de vidrio (50 mL; BD Yale ${ }^{\circledR}$, Brasil) a las 0, 2, 4, 6, 9, 12, 24, 36,48 y $72 \mathrm{~h}$ para estimar la producción acumulada de gas total a las $72 \mathrm{~h}$. Los $\mathrm{mL}$ gas producidos se usaron para obtener los parámetros de la cinética de producción de gas con la ecuación $\mathrm{V}=\mathrm{V}_{\mathrm{m}} \times\{1+\exp (2+4(\lambda-$ t)) $\}^{-1}$; dónde: $V$ es el volumen de gas en el tiempo $t, V_{m}$ es el volumen máximo a $t=\infty, S$ es una constante de velocidad llamada tasa específica (velocidad máxima / volumen máximo), y $\lambda$ es una constante de integración equivalente a un plazo de retraso (Schofield \& Pell 1995, p. 3457).

\section{GAS METANO $\left(\mathrm{CH}_{4}\right)$}

La producción de $\mathrm{CH}_{4}$ (5 determinaciones independientes por muestra de forraje) se midió a las 24, 48 y $72 \mathrm{~h}$. Un tubo de Taygon ${ }^{\circledR}(2.38 \mathrm{~mm} \varnothing$ interno y $45 \mathrm{~cm}$ de longitud) con agujas hipodérmicas (20 G x $32 \mathrm{~mm}$ ) en los extremos, se usó para acoplar un biodigestor con un vial trampa lleno de solución $2 \mathrm{M}$ de $\mathrm{NaOH}$ (Stolaroff et al. 2008, p. 2729) modificado según TorresSalado et al. (2018, p. 57). 


\section{ÁCIDOS GRASOS VOLÁTILES (AGV)}

A las $72 \mathrm{~h}$, se tomó $1 \mathrm{~mL}$ de muestra, se le agregaron 0,25 mL de ácido metafosfórico al 25 \% y se centrifugó a $18800 \mathrm{~g}$ durante $10 \mathrm{~min}$. En el sobrenadante se determinaron los AGV mediante cromatografía de gases (Perkin Elmer ${ }^{\circledR}$, modelo Claurus 580, USA) equipado con detector de ionización de llama y columna capilar (Elite FFAP, Agilent $^{\circledR}$ ) de $30 \mathrm{~m}$ x 0,25 mm; usando helio como gas acarreador a una presión constante de $10 \mathrm{psi}, \mathrm{H}_{2}$ y aire para generar flama con flujo de $40 \mathrm{y}$ $400 \mathrm{~mL} \mathrm{~min}^{-1}$. Las temperaturas del horno, inyector y columna fueron 80,240 y $250{ }^{\circ} \mathrm{C}$ y se inyectó $1 \mu \mathrm{L}$ de muestra. Los tiempos de retención fueron 3,7, 4,3 y 5,2 min para los ácidos acético, propiónico y butírico, respectivamente.

\section{CONTEO DE BACTERIAS TOTALES}

A $1 \mathrm{~mL}$ del medio contenido en el biodigestor a $72 \mathrm{~h}$ de incubación, se añadieron 0,25 mL de formaldehido al $10 \%$. La cantidad de bacterias totales (3 muestras independientes por forraje) se calculó realizando el conteo directo en una cámara Petroff-Hausser (Hausser \#39000, Electron Mycroscopy Sciences, USA), con un área de $0,0025 \mathrm{~mm}^{2}$ y profundidad de $0,02 \mathrm{~mm}$. Para el recuento se usó un microscopio (BX31, Olympus, USA) a una magnificación de 1000. La cantidad de bacterias se calculó con la fórmula: Cantidad de bacterias $=$ (promedio) (factor de dilución, 2X107) (Hernández-Morales et al. 2018, p. 110; Sánchez-Santillán \& Cobos-Peralta 2016, p. 568)

\section{DEGRADACIÓN DE MATERIA SECA, FIBRA NEUTRO DETERGENTE Y FIBRA ÁCIDO DETERGENTE}

Se siguió la metodología de Hernández-Morales et al. (2018). La muestra residual del biodigestor se filtró a través de bolsas ANKOM $^{\circledR}$ taradas en seco ( 5 determinaciones independientes por forraje) y selladas a posteriori. El total de bolsa + residuo se secó a 60 ${ }^{\circ} \mathrm{C}$ durante $24 \mathrm{~h}$ en estufa de aire forzado. La degra-

Tabla I. Análisis bromatológico de nueve forrajes utilizados en la alimentación de rumiantes del trópico seco mexicano (Bromatological analysis of nine forages used in the feeding of ruminants of the Mexican dry tropic).

\begin{tabular}{lcccc}
\hline Forraje & PC $(\%)$ & FND $(\%)$ & FAD $(\%)$ & Ce $(\%)$ \\
\hline Bermuda & $11,60^{\mathrm{b}}$ & $76,32^{\mathrm{a}}$ & 50,20 & $8,63^{\mathrm{e}}$ \\
Bramilla & $10,19^{\mathrm{c}}$ & $72,64^{\mathrm{ac}}$ & 46,11 & $9,62^{\mathrm{d}}$ \\
Estrella & $8,76^{\mathrm{d}}$ & $77,33^{\mathrm{a}}$ & 46,54 & $8,78^{\mathrm{e}}$ \\
Insurgente & $8,78^{\mathrm{d}}$ & $71,65^{\mathrm{acd}}$ & 52,63 & $13,30^{\mathrm{b}}$ \\
Llanero & $4,37^{\mathrm{e}}$ & $70,75^{\mathrm{cde}}$ & 44,78 & $8,06^{\mathrm{e}}$ \\
Mombaza & $16,17^{\mathrm{a}}$ & $69,37^{\text {cde }}$ & 45,77 & $13,03^{\mathrm{b}}$ \\
Mulato & $11,88^{\mathrm{b}}$ & $65,44^{\mathrm{e}}$ & 40,63 & $13,43^{\mathrm{b}}$ \\
Pangola & $7,76^{\mathrm{d}}$ & $74,22^{\mathrm{a}}$ & 41,62 & $10,84^{\mathrm{c}}$ \\
Pará & $15,98^{\mathrm{a}}$ & $66,82^{\mathrm{de}}$ & 41,92 & $14,86^{\mathrm{a}}$ \\
EEM & 0,708 & 0,810 & 1,232 & 0,469
\end{tabular}

$a, b, c, d, e$ Valores promedio que difieren en columna no comparten literal, Tukey $(P<0,05)$.

PC: proteína cruda; FND: fibra neutro detergente; FAD: fibra ácido detergente; Ce: cenizas; EEM: Error estándar de la media. dación in vitro aparente de la materia seca se calculó como DEGMS $(\%)=100 *$ (muestra inicial - muestra residual / muestra inicial). Las bolsas ANKOM $^{\circledR}$ con los residuos de MS se sellaron a calor para determinar FND y FAD no digeridas según Van Soest et al. (1991, pp. 3584-3586). El porcentaje de degradación de FND y FAD se calcularon como DEGFND $(\%)=100 *(F N D$ inicial - FND residual)/ FND inicial y DEGFAD (\%) = $100 *$ (FAD inicial - FAD residual)/ FAD inicial).

\section{ANÁLISIS ESTADÍSTICO}

El análisis bromatológico, la producción de gas total, la cinética de producción de gas, la producción de gas metano, los ácidos grasos volátiles, el conteo de bacterias y las degradaciones de materia seca, fibra neutro detergente y fibra ácido detergente de los nueve forrajes se analizaron en un diseño completamente al azar. El modelo estadístico fue: $Y_{\mathrm{ij}}=\mu+\tau_{\mathrm{i}}+\varepsilon_{\mathrm{ij}}$; donde: $Y_{i j}$ son las variables de respuesta en la repetición j, de la muestra $i ; \mu$ es la media general; $\tau_{i}$ es el efecto del i-ésimo tipo de sustrato; $\varepsilon_{\mathrm{ij}}$ es el error aleatorio del i-ésimo tipo de muestra en la j-ésima repetición. Los datos se analizaron usando el procedimiento GLM de SAS ${ }^{\circledR}$ (SAS Institute Inc. 2011) y las medias por tratamiento se compararon con la prueba de Tukey $(\mathrm{P}<0,05)$.

\section{RESULTADOS}

Los pastos mombaza y pará promediaron mayor contenido de PB con 16,08 \% y difieren estadísticamente con el resto de los pastos. Los pastos llanero, mombaza, mulato y pará presentaron menor contenido de FND. En el contenido de FAD no mostraron diferencias estadísticas los pastos. Los pastos bermuda, estrella y llanero tuvieron menor contenido de Ce (Tabla I).

La producción de metano $\left(\mathrm{CH}_{4}\right)$ en las primeras 24 $\mathrm{h}$ fue mayor en los pastos bramilla, llanero, mombaza y pangola y en los pastos pará y bermuda fue menor. A las $48 \mathrm{~h}$, el pasto pará produjo menor $\mathrm{CH}_{4}$ y el pasto bermuda mayor. A las $72 \mathrm{~h}$ de incubación, los pastos estrella, insurgente y pangola presentaron mayor producción de $\mathrm{CH}_{4}$. Los pastos bermuda y pará mostraron menor producción acumulada de $\mathrm{CH}_{4}$ a las $72 \mathrm{~h}$ y el resto de pastos no difirieron estadísticamente su producción (Tabla II).

El pasto mombaza produjo mayor cantidad de gases totales a las $72 \mathrm{~h}$, donde $\mathrm{CH}_{4}$ representó $40,3 \%$. Los pastos bermuda y pará presentaron menor cantidad de $\mathrm{CH}_{4}$, pero representó 57,72 y 51,81\% del total de gas producido. El pasto insurgente mostró $65,11 \%$ de producción de $\mathrm{CH}_{4}$ respecto al total de gas producido (Tabla II).

El Vm del pasto bermuda fue menor y del pasto mombaza mayor (Tabla III). La S del pasto insurgente fue mayor, lo que representó 58,8 \% mejor tasa que del pasto mombaza. El pasto pará mostró menor $S$, pero no se afectó su Vm comparado con pasto bermuda, quién produjo menor Vm (Tabla III). El pasto insurgente requirió mayor tiempo para que las bacterias se adhirieran $(\lambda)$; en contraste, pangola y llanero necesitaron de menor tiempo (Tabla III). 


\begin{tabular}{|c|c|c|c|c|c|}
\hline \multirow{2}{*}{ Forraje } & \multicolumn{3}{|c|}{ Producción parcial de $\mathrm{CH}_{4}$} & \multirow{2}{*}{$\begin{array}{l}\text { Producción } \\
\text { acumulada } \\
\mathrm{CH}_{4}\end{array}$} & \multirow{2}{*}{$\begin{array}{c}\text { Producción } \\
\text { acumulada } \\
\text { gas total }\end{array}$} \\
\hline & 24 & 48 & 73 & & \\
\hline Bermuda & $15,48^{c}$ & $14,64^{\mathrm{a}}$ & $7,31^{\mathrm{bcd}}$ & $27,28^{\mathrm{b}}$ & $47 ?$ \\
\hline Bramilla & $25,88^{a}$ & $12,48^{\mathrm{ab}}$ & $6,48^{\mathrm{cd}}$ & $38,59^{a}$ & 87,1 \\
\hline Estrella & $22,95^{\mathrm{ab}}$ & $11,48^{\mathrm{bc}}$ & $10,64^{a}$ & $44,90^{\mathrm{a}}$ & $86,35^{\mathrm{b}}$ \\
\hline Insurgente & $21,31^{\mathrm{b}}$ & $10,49^{\mathrm{bc}}$ & $9,99^{a b}$ & $44,62^{\mathrm{a}}$ & $68,53^{c}$ \\
\hline Llanero & $25,94^{a}$ & $10,48^{\mathrm{bc}}$ & ז & $43,23^{a}$ & . \\
\hline Mombaza & $25,98^{\mathrm{a}}$ & $10,48^{\mathrm{bc}}$ & $7,33^{\mathrm{bcd}}$ & $42,63^{a}$ & $105,78^{\mathrm{a}}$ \\
\hline Mulat & $21,45^{b}$ & 9 & 7,3 & 3 & $85,80^{\mathrm{b}}$ \\
\hline Pangola & $25,95^{a}$ & $9,49^{c}$ & $8,65^{\mathrm{abc}}$ & $40,62^{a}$ & $83,18^{b}$ \\
\hline Pará & $15,98^{c}$ & $5,32^{\mathrm{d}}$ & 5,5 & 27 & 54 \\
\hline EEM & 2,388 & 0,77 & 0,400 & 0,337 & 1,128 \\
\hline \multicolumn{6}{|c|}{$\begin{array}{l}\mathrm{a}, \mathrm{b}, \mathrm{c}, \mathrm{d}, \mathrm{e} \text { Valores promedio que difieren en columna no comparten } \\
\text { literal, Tukey }(\mathrm{P}<0,05) \text {. } \\
\mathrm{CH}_{4} \text { : metano; EEM: Error estándar de la media. }\end{array}$} \\
\hline
\end{tabular}

La DEGMS fue menor a $50 \%$ en todos los pastos evaluados (Tabla IV). Los pastos mombaza y mulato promediaron mayor DEGMS con $46,08 \%$, en contraste la DEGMS de los pastos bermuda y pangola fue menor (Tabla IV). La DEGFND fue mayor en pasto mombaza (Tabla IV). La DEGFAD en los pastos bermuda, insurgente, mombaza y mulato fue mayor (Tabla IV).

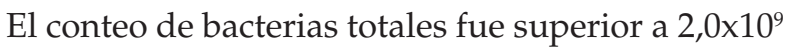
bacterias $\mathrm{mL}^{-1}$ cuando se usaron como fuentes de carbono los pastos bramilla, estrella, pará y mombaza. Sin embargo, el conteo se redujo 50 \% cuando se uso el pasto bermuda (Tabla IV). El contenido de acetato,

Tabla III. Cinética de producción de gas in vitro de nueve forrajes utilizados en la alimentación de rumiantes del trópico seco mexicano (Kinetics of in vitro gas production of nine forages used in the feeding of ruminants of the Mexican dry tropic).

\begin{tabular}{lccc}
\hline Forraje & $\mathrm{Vm}\left(\mathrm{mL} \mathrm{g}^{-1} \mathrm{MS}\right)$ & $\mathrm{S}\left(\mathrm{h}^{-1}\right)$ & $\lambda(\mathrm{h})$ \\
\hline Bermuda & $45,67^{\mathrm{e}}$ & $0,037^{\mathrm{c}}$ & $22,81^{\mathrm{c}}$ \\
Bramilla & $84,97^{\mathrm{bc}}$ & $0,032^{\mathrm{d}}$ & $12,50^{\mathrm{f}}$ \\
Estrella & $82,60^{\mathrm{bc}}$ & $0,037^{\mathrm{c}}$ & $13,89^{\text {ef }}$ \\
Insurgente & $70,32^{\mathrm{dc}}$ & $0,054^{\mathrm{a}}$ & $38,04^{\mathrm{a}}$ \\
Llanero & $85,08^{\mathrm{b}}$ & $0,032^{\mathrm{ed}}$ & $11,52^{\mathrm{fg}}$ \\
Mombaza & $105,17^{\mathrm{a}}$ & $0,034^{\mathrm{cd}}$ & $21,14^{\mathrm{cd}}$ \\
Mulato & $82,10^{\mathrm{bc}}$ & $0,043^{\mathrm{b}}$ & $17,30^{\mathrm{de}}$ \\
Pangola & $82,44^{\mathrm{bc}}$ & $0,028^{\mathrm{e}}$ & $7,64^{\mathrm{g}}$ \\
Pará & $66,70^{\mathrm{d}}$ & $0,012^{\mathrm{f}}$ & $28,62^{\mathrm{b}}$ \\
EEM & 2,326 & 0,0016 & 1,26 \\
\hline
\end{tabular}

$\mathrm{a}, \mathrm{b}, \mathrm{c}, \mathrm{d}, \mathrm{e}$ Valores promedio que difieren en columna no comparten literal, Tukey $(P<0,05)$.

Vm: volumen máximo de gas; $S$ : tasa de producción de gas; $\lambda$ : tiempo lag; EEM: error estándar de la media. butirato y ácidos grasos volátiles totales no difirieron estadísticamente entre pastos, mientras el contenido de propionato varió entre pastos (Tabla V).

\section{DISCUSIÓN}

El análisis bromatológico de los pastos usados en la presente investigación y los reportados por otros autores son consecuencia de las condiciones agronómicas en que se producen (Valenciaga \& Chongo 2004, p. 345; Barahona et al. 2003, p. 1256), de las características vegetativas de los pastos (Aguirre 2013, pp. 43-44) y la edad de corte, porque se incrementa la pared celular y el contenido de lignina (Gándara et al. 2017, p. 74). El contenido de PB en mombaza y pará (Tabla I) es mayor que lo reportado por Ortega-Aguirre et al. (2015, p. 295), Mesquita \& Neres (2008, p. 205), Cardona et al. (2002, p. 242) y Ojo et al. (2017, p. 471). Mesquita y Neres (2008, p. 205) y Ortega-Aguirre et al. (2015, p. 295) publicaron contenidos de 15,19 y 9,33 \% de PB en cortes de mombaza con $20 \mathrm{~cm}$ de altura; Cardona et al. (2002, p. 242) reportaron $8,17 \%$ de PB en pasto pará; y Ojo et al. (2017, p. 471) calcularon 5,9\% de PB en pasto natural.

La edad de corte de los pastos evaluados en la presente investigación no infirió en el contenido de lignina y celulosa (FAD), por lo que la variación se presentó en el contenido de hemicelulosa. Aquellos pastos con menor concentración de FND promediaron 24,82 \% de hemicelulosa (Tabla I), en los demás pastos fue variable. El contenido de FND del pasto mombaza en el presente estudio fue menor que lo reportado por Freitas et al. (2007, p. 5) y Mesquita y Neres (2008, p. 205) y similar en FAD; ya que cuantificaron 73,5 y $74,27 \%$ de FND y 41,06 y 40,86 \% de FAD. Cardona et al. (2002, p. 242) publicaron $70,48 \%$ FND para pasto estrella; valores menores que lo obtenido en el presente trabajo. En contraste, en pasto pará Cardona et al. (2002, p. 242) obtuvieron valores mayores que el presente estudio. El pasto estrella de la presente investigación mostró valores de Ce similares a Cardona et al. (2002, p. 242); pero, el contenido de Ce del pasto pará fue mayor que lo informado por Cardona et al. (2002, p. 242) y OrtegaAguirre et al. (2015, p. 295).

Posada-Ochoa et al. (2014, p. 145) reportaron 254,46 $\mathrm{mL} \mathrm{g}^{-1}$ MS de gas y 43,62 mL g-1 MS de $\mathrm{CH}_{4}$ a las 48 h de incubación de Pennisetum clandestinum; valores mayores que los resultados obtenidos en el presente trabajo. Galindo et al. (2003, p. 185) publicaron $35 \mathrm{~mL}$ de $\mathrm{CH}_{4} \mathrm{~g}^{-1} \mathrm{MS}$ de Cynodon nlenfuensis a las $72 \mathrm{~h}$ de fermentación, 228,9\% mayor que el mismo pasto en el presente estudio. Estas diferencias de producción de gas se atribuyen a la disponibilidad de carbohidratos estructurales y no estructurales para los microorganismos durante la fermentación (Elghandour et al. 2016, p. 15; Ferro et al. 2017, p. 240) como la celulosa (Vargas et al. 2014, p. 402) no lignificada (Ojo et al. 2017, p. 472). Por lo que la producción de gas y $\mathrm{CH}_{4}$ se relacionan directamente con la composición de la pared celular de los pastos (Tiemman et al. 2008, pp. 1800-1801).

El Vm (Tabla III) presentó comportamiento similar a la producción de gas total (Tabla II) porque la primera se estimó a partir de un modelo estadístico y la 


\begin{tabular}{|c|c|c|c|c|}
\hline Forraje & $\begin{array}{c}\text { DEGMS } \\
(\%)\end{array}$ & $\begin{array}{c}\text { DEGFND } \\
(\%)\end{array}$ & $\begin{array}{c}\text { DEGFAD } \\
(\%)\end{array}$ & $\begin{array}{c}{[\mathrm{B}]} \\
\left(10^{9} \text { células }\right. \\
\left.\mathrm{mL}^{-1}\right)\end{array}$ \\
\hline Bermuda & $34,46^{\text {ef }}$ & $37,28^{\text {cd }}$ & $51,61^{\mathrm{ab}}$ & $1,15^{d}$ \\
\hline Bramilla & $41,46^{c}$ & $37,68^{\text {cd }}$ & $46,39^{b c}$ & $2,92^{a}$ \\
\hline Estrella & $39,92^{\mathrm{cd}}$ & $40,34^{c}$ & $44,70^{c}$ & $2,88^{a}$ \\
\hline Insurgente & $42,72^{\mathrm{bc}}$ & $47,66^{b}$ & $54,38^{a}$ & $1,63^{\text {cd }}$ \\
\hline Llanero & $34,17^{f}$ & $26,73^{\mathrm{e}}$ & $27,94^{\mathrm{e}}$ & $1,90^{\mathrm{bc}}$ \\
\hline Mombaza & $46,96^{\mathrm{a}}$ & $52,82^{\mathrm{a}}$ & $54,70^{a}$ & $2,03^{b c}$ \\
\hline Mulato & $45,20^{\mathrm{ab}}$ & $47,42^{\mathrm{b}}$ & $52,37^{a}$ & $1,90^{\mathrm{bc}}$ \\
\hline Pangola & $37,42^{\mathrm{de}}$ & $35,58^{d}$ & $36,12^{d}$ & $1,57^{\mathrm{cd}}$ \\
\hline Pará & $41,24^{c}$ & $40,80^{c}$ & $36,66^{d}$ & $2,57 a^{b}$ \\
\hline EEM & 0,72 & 1,261 & 1,542 & 0,119 \\
\hline \multicolumn{5}{|c|}{$\begin{array}{l}\text { a,b,c,d,e Valores promedio que difieren en columna no comparten } \\
\text { literal, Tukey }(P<0.05) \text {. } \\
\text { DEGMS: degradación de la materia seca a las } 72 \mathrm{~h} \text { de fermentación; } \\
\text { DEGFND: degradación de fibra neutro detergente a las } 72 \mathrm{~h} \text { de } \\
\text { fermentación; } D E G F A D: \text { degradación de fibra ácida detergente a } \\
\text { las } 72 \mathrm{~h} \text { de fermentación; [B]: concentración de bacterias totales } \\
\text { por } \mathrm{mL}^{-1} \text {; EEM: error estándar de la media. }\end{array}$} \\
\hline
\end{tabular}

segunda fue una medición directa a las 72 h; por lo que ambos se relacionan con la degradabilidad de la materia seca (Saminathan et al. 2015, p. 2745). Los valores de $\mathrm{Vm}$ y $\mathrm{S}$ en la presente investigación se debe a la composición química bromatológica (Sánchez-Santillán et al. 2015, pp. 4913-4914) y contenido de lignina (Ojo et al. 2017, p. 472) de los pastos. El tiempo lag $(\lambda)$ es una estimación del tiempo que tardan las bacterias en adherirse; pero, al obtenerse usando un modelo estadístico, los valores pueden sobre o subestimarse como en el presente estudio (Tabla III).

Molina et al. (2013, p. 23) y Gaviria et al. (2015, p. 59) publicaron Vm y S mayores que el presente estudio fermentando Megathyrsus maximus a $72 \mathrm{~h}$; pero, $\lambda$ fue similar comparado con algunos pastos del presente estudio. Esto se puede asumir a que la eficiencia de utilización de los sustratos por microrganismos ruminales depende de la composición química, la cual influyó sobre los valores de Vm, S y $\lambda$ (Gaviria et al. 2015, pp. 59-60). Los valores reportados en el presente estudio de la cinética de producción de gas se pueden asumir al nivel de lignina presente en los pastos; ya que, la lignina al entrelazarse con los carbohidratos estructurales limita el acceso a los microorganismos (Fondevila et al. 2002, p. 11; Gaviria et al. 2015, p. 60).

Las DEGMS inferiores a 60 \% (Tabla IV) de los pastos se asume a los contenidos de FND y FAD (Coley \& Barone 1996, p. 308; Apráez et al. 2012, p. 7). Además, los valores de DEGMS en el presente estudio (Tabla IV) son menores que lo reportado por Combellas \& González (1972, pp. 5-6) y Gaviria et al. (2015, p. 60); quienes publicaron digestibilidades aparentes mayores a $60 \%$ en Cenchrus ciliaris y a $50 \%$ en Megathyrsus maximus. Estas diferencias se asumen a que los autores
Tabla V. Estimación de ácidos grasos volátiles ( $\mathrm{mM}$ $\mathrm{L}^{-1}$ ) de nueve forrajes utilizados en la alimentación de rumiantes del trópico seco mexicano (Estimation of volatile fatty acids $\left(\mathrm{mM} \mathrm{L}^{-1}\right)$ of nine forages used in the feeding of ruminants of the Mexican dry tropic).

\begin{tabular}{lcccc}
\hline Forraje & Acetato & Propionato & Butirato & AGV \\
\hline Bermuda & 22,38 & $6,14^{\mathrm{ab}}$ & 1,54 & 30,06 \\
Bramilla & 17,99 & $4,98^{\mathrm{ab}}$ & 1,81 & 30,93 \\
Estrella & 14,66 & $4,04^{\mathrm{b}}$ & 1,19 & 23,81 \\
Insurgente & 18,35 & $6,75^{\mathrm{ab}}$ & 1,24 & 26,34 \\
Llanero & 23,38 & $6,12^{\mathrm{ab}}$ & 1,63 & 31,14 \\
Mombaza & 24,98 & $6,89^{\mathrm{ab}}$ & 1,75 & 33,61 \\
Mulato & 23,77 & $8,22^{\mathrm{a}}$ & 1,79 & 33,79 \\
Pangola & 16,10 & $4,30^{\mathrm{b}}$ & 1,18 & 21,58 \\
Pará & 12,38 & $3,63^{\mathrm{b}}$ & - & - \\
EEM & 1,229 & 1,116 & 0,357 & 0,074 \\
\hline a,b,c,d,e Valores & promedio que difieren en columna no comparten
\end{tabular}

a,b,c,d,e Valores promedio que difieren en columna no comparten literal, Tukey $(P<0.05)$.

AGV: ácidos grasos volátiles; EEM: error estándar de la media.

citados usaron gramíneas con una edad de rebrote de 22 y 29 días, diferencias de 35 y 27 días al presente estudio; ya que, el contenido de PB, FND y FAD se diferenció por la edad entre los pastos usados (García et al. 2017, pp. 692-693). La DEGMS en el presente estudio infirió que los pastos con 56 días de rebrote no aportaron los nutrientes para el desarrollo óptimo de microorganismos ruminales (Gaviria et al. 2015, p. 60), lo que se manifestó en la producción de gas (Vargas et al. 2014, p. 403).

Los valores medios de la DEGFND de los pastos se asume al tipo de carbohidratos que componen a la FND (Trujillo et al. 2010, p. 56); ya que, la FND se compone de una fracción degradable y una fracción indigestible completa (Nordheim-Viken et al. 2009, pp. 52-53; Lopes et al. 2015, p. 5). Los pastos bermuda, bramilla, llanero y pangola mostraron degradaciones menores a 40 \% (Tabla IV), lo que indicó una disminución en la disponibilidad de energía y consumo potencial de la materia seca (Hoffman et al. 2007, p. 2) bajo las condiciones de la presente investigación. Juárez et al. (2001, p. 6) publicó DEGFND mayores a $70 \%$ en pastos Brachiaria decumbes, Brachiaria brizantha, Panicum maximun y Andropogon gayanus con 60 días de rebrote, valores mayores que lo reportado en el presente estudio.

Galindo et al. (2003, p. 185) reportaron una concen-

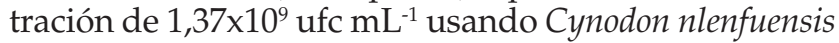
como sustrato. Sánchez-Santillán et al. (2016, p. 580) publicaron una concentración de $7,21 \times 10^{8}$ bacterias $\mathrm{mL}^{-1}$ en medios de cultivo con celulosa cristalina. Hernández-Morales et al. (2018, pp. 112-113) determinaron una población de $10^{9}$ bacterias $\mathrm{mL}^{-1}$ en vainas de diferentes leguminosas tropicales. Estos autores reportaron valores similares al presente estudio (Tabla IV), por lo que se puede inferir que la concentración de bacterias totales no influyó en la producción de gas y degradación de la materia seca. 
El tipo de ácidos grasos volátiles se asocia directamente con el tipo de carbohidratos fermentados (Vargas et al. 2014, p. 403). La variación de propionato en los pastos evaluados (Tabla V) se asume al contenido celular de los pastos (Tabla I); ya que, el propionato es un residuo de la fermentación ruminal de almidones o azucares (Bedoya-Mazo et al. 2016, p. 6). Galindo et al. (2003, p. 185) publicaron una concentración de 89,92 AGV con una relación acético-propiónico-butírico-isovalérico de 67,37-19,93-9,50-2,08, valores mayores que el presente estudio.

\section{CONCLUSIONES}

Con respecto a la información publicada sobre pastos tropicales, el pasto bermuda presentó contenido promedio de proteína bruta, alto de fibras detergentes y cenizas; una baja producción de gas total, donde metano representó 57,7 \%; y la degradación de materia seca y de fibra neutro detergente fue menor y de fibra ácido detergente mayor a $50 \%$. El pasto bramilla se mostró dentro del promedio de proteína bruta, alto de fibras detergentes y cenizas; su producción de gas total fue alta con 44,3\% de metano; y todas las degradaciones fueron menores a $50 \%$. El pasto estrella tuvo bajo contenido de proteína bruta, alto de fibras detergente y cenizas; la producción de gas fue alta, del cual 52,0 \% fue metano; y todas las degradaciones fueron menores a $50 \%$. El pasto insurgente fue bajo en proteína bruta y alto en fibras detergentes y cenizas; su producción de gas fue baja y el metano aportó 65,1%; la degradación de materia seca y de fibra neutro detergente fue menor y la fibra ácido detergente mayor a $50 \%$. El pasto llanero fue bajo en proteína bruta, alto en fibras detergentes y cenizas; la producción de gas fue alta con 51,6 \% de metano; y presentó las menores degradaciones de materia seca y fibras detergentes. El pasto mombaza fue alto en proteína bruta, promedio en fibras detergentes y alto en cenizas; la producción de gas fue mayor, donde el metano fue 40,3 \%; la degradación de materia seca fue menor y las degradaciones de las fibras detergentes fueron mayores a $50 \%$. El pasto mulato fue promedio en proteína bruta, alto en fibras detergentes y promedio en cenizas; la producción de gas fue alta, donde el metano fue $85,8 \%$; y la degradación de materia seca y de fibra neutro detergente fue menor y fibra ácido detergente mayor a $50 \%$. El pasto pangola fue bajo en proteína bruta, alto en fibras detergentes y cenizas; la producción de gas fue alta, donde 48,8 \% fue metano; y las degradaciones de materia seca y fibras detergentes fueron menores de $38 \%$. El pasto pará presentó alto contenido de proteína bruta, promedio en fibras detergentes y alto en cenizas; la menor producción de gas con 51,7 \% de metano; y todas las degradaciones menores a $50 \%$.

\section{AGRADECIMIENTOS}

A la Universidad Autónoma de Guerreo por el financiamiento del proyecto "Estimación de los gases efecto invernadero de los principales forrajes utilizados en la alimentación de rumiantes en la Costa Chica, Guerrero mediante la técnica de producción de gas in vitro" dentro de la convocatoria de Proyectos de Inves- tigación Semilla 2014. Así como, al M. V. Z. Amadeo García Morales por su apoyo en campo y laboratorio para ejecutar el presente experimento como parte de su trabajo de tesis de licenciatura.

\section{BIBLIOGRAFÍA}

Aguirre, OJ 2013, 'Características nutricionales de algunas leñosas forrajeras', Abanico Veterinario, vol. 3, núm. 3, pp.42-51.

AOAC 2005, 'Official Methods of Analysis' (18th Ed), Washinton D.C: AOAC International.

Apráez, JE, Delgado, JM \& Narvaez, JP 2012, 'Composición nutricional, degradación in vitro y potencial de producción de gas, de herbáceas, arbóreas y arbustivas encontradas en el trópico alto de Nariño', Livestock Research for Rural Development, vol. 24, núm. 3, pp.1-11.

Barahona, R, Lascano, CE, Narvaez, N, Owen, E, Morris, P \& Theodorou MK 2003, 'In vitro degradability of mature and immature leaves of tropical forage legumes differing in condensed tannin and non-starch polysaccharide content and composition' Journal of the Science of Food and Agriculture, vol. 83, núm. 2, pp.1256-1266.

Bedoya-Mazo, S, Noguera, RR \& Posada, SL 2016 'Efecto de la especie donadora de inóculo ruminal sobre la degradación de la materia seca y producción de metano in vitro', Livestock Research for Rural Development, vol. 28, p. 86.

Cardona, MG, Sorza, JD, Posada, SL, Carmona, JC, Ayala, SA \& Alvarez OL 2002, 'Establecimiento de una base de datos para la elaboración de tablas de contenido nutricional de alimentos para animales', Revista Colombiana de Ciencias Pecuarias, vol. 15, núm. 2, pp. 240-246.

Castro-Hernández, H, Domínguez-Vara, IA, Morales-Almaráz, E \& Huerta-Bravo, M 2017, 'Composición química, contenido mineral y digestibilidad in vitro de raigrás (Lolium perenne) según intervalo de corte yépoca de crecimiento', Revista Mexicana de Ciencias Pecuarias, vol. 8, núm. 2, pp. 201-210.

Coley, PD \& Barone, JA 1996, 'Herbivory and Plant Defenses in Tropical Forests', Annual Reviews Ecology System, vol. 27, pp. 305-335.

Combellas, J \& González J 1972, 'Rendimiento y valor nutritivo de forrajes tropicales. 2. Cenchrus ciliaris L. cv. Biloela', Agronomia Tropical, vol. 22, núm. 6, pp. 579-586.

Elghandour, MMY, Kholif, AE, Lopez, S, Mendoza, GD, Odongo, NE \& Salem AZM 2016 'In vitro gas, methane and carbon dioxide productions of high fibrous diet incubated with fecal inocula from horses fed live yeasts in response to the supplementation with different yeast additives', Journal of Equine Veterinary Science, vol. 38, pp. 64-71.

Faría, MJ 2006, 'Manejo de pastos y forrajes en la ganadería de doble propósito' in Montiel NU et al (eds), X Seminario Manejo y utilización de pastos y forrajes en sistemas de producción animal, Maracaibo, Venezuela, pp. 1-9.

Ferro, MM, Zanine AM, Castro WJR \& Souza AL 2017 'Cinética de fermentação ruminal in vitro de silagem de cana-de-açúcar com resíduo de cervejaria desidratado', Archivos de Zootecnia, vol. 66, núm. 254, pp: 237-242.

Fondevila, M, Nogueira-Filho, JCM \& Barrios-Urdaneta A 2002, 'In vitro microbial fermentation and protein utilisation of tropical forage legumes', Animal Feed Science and Technology, vol. 95, pp. 1-14.

Freitas, KR, Rosa B, Ruggiero, JA, do Nascimento, JL, Heineman, AB, Macedo, RF, Naves, MAT \& de Oliveira IP 2007, 'Avaliação da composição químico - bromatológica do capim mombaça (Panicum maximum jacq.) submetido a diferentes doses de nitrogênio', Bioscience Journal, vol. 23, núm. 3, pp. 1-10.

Galindo, J, Elías, A, Palenzuela, T, Pérez MC \& Aldama Al 2003, 'Efecto del momensín en la producción de metano in vitro en tres sistemas ecológicos ruminales', Revista Cubana de Ciencia Agrícola, vol. 37, núm. 2, pp. 183-188.

Gándara, L, Borrajo, Cl, Fernández, JA \& Pereira MM 2017, 'Efecto de la fertilización nitrogenada y la edad del rebrote sobre el valor nutritivo de Brachiaria brizantha cv. "Marandu", Revista FCA Uncuyo, vol. 49, núm. 1, pp. 69-77. 
García, BA, Sánchez, SP, Rojas, GAR, Torres, SN, Herrera, PJ, Maldonado, PMA, Mendoza, NMA \& Mayren, MFJ 2017, 'Calidad de híbridos del género Brachiaria a diferentes frecuencias de corte', in Basurto RG et al (eds), LIII Reunión Nacional de Investigación Pecuaria, Acapulco, Guerrero, pp. 692-694

Gaviria, X, Naranjo, JF \& Barahona, R 2015, 'Cinética de fermentación in vitro de Leucaena leucocephala y Megathyrsus maximus y sus mezclas, con o sin suplementación energética. Pastos y forrajes, vol. 38, núm. 1, pp.55-63.

Hernández-Morales, J, Sánchez-Santillán, P, Torres-Salado, N, HerreraPérez, J, Rojas-García, AR, Reyes-Vázquez, I \& Mendoza-Núñez MA 2018 , 'Composición química y degradaciones in vitro de vainas y hojas leguminosas arbóreas del trópico seco de México' Revista Mexicana de Ciencias Pecuarias, vol. 9, núm. 1, pp. 105-120.

Hoffman, PC, Lundberg, KM, Bauman, LM, Shaver, RD \& ContrearasGovea, FE 'Digestibiliad in vitro del FDN (fibra detergente neutra): el debate de 30 vs 48 horas', Universiad de Wisconsin, Focus Forage, vol. 5, pp. 1-4.

Juárez, LF, Contreras, JJL \& Montero, LM 2001, 'Tasa de cambios con relación a edad en rendimiento, composición química y digestibilidad de cinco pastos tropicales', in XIV Reunión Cientifica-Tecnologica Forestal y Agropecuaria, Veracruz, México, pp. 1-8.

Lopes, F, Cook, DE \& Combs, DK 2015, 'Effects of varying dietary ratios of corn silage on digestion of neutral detergent fiber in lactating dairy cows', Journal Dairy Science, vol. 98, núm. 9, pp.2-13.

Mesquita, EE \& Neres, MA 2008, 'Morfogênese e composição bromatológica de cultivares de Panicum maximum em função da adubação nitrogenada', The Revista Brasileira de Saúde e Produção Animal, vol. 9, núm. 2, pp. 201-209.

Molina, BIC, Manuel, CJ, Montoya, S, Correa, LGA \& Barahona, RR 2013, 'Producción de metano in vitro de dos gramíneas tropicales solas y mezcladas con Leucaena leucocephala o Gliricidia sepium', CES Medicina Veterinaria y Zootecnia, vol. 8, no. 2, pp.15-31.

Muñoz-González, JC, Huerta-Bravo, M, Lara, BA, Rangel, SR \& de la Rosa AJL 2016, 'Producción y calidad nutrimental de forrajes en condiciones del trópico húmedo de México, Revista Mexicana de Ciencias Agrícolas, vol. Esp, núm. 16, pp. 3315-3327.

Nordheim-Viken, H \& Volden, H 2009 'Effect of maturity stage, nitrogen fertilization and seasonal variation on ruminal degradation characteristics of neutral detergent fibre in timothy (Phleum pretense L.)', Animal Feed Science and Technology, vol. 149, pp.30-59.

Ojo, VOA, Adeoye SA, Oni AO, Adelusi OO, Yusuf KO, Jalaosho AO, Olanite JA \& Onifade OS 2017, 'Valor nutritivo de los recursos alimenticios procesados procedentes de pastos naturales en South-West, Nigeria', Archivos de Zootecnia, vol. 66, núm. 256, pp: 469-474.

Ortega-Aguirre, CA, Lemus-Flores, C, Bugarín-Prado, JO, Alejo-Santiago, G, Ramos-Quirarte, A, Grageola-Núñez, O \& Bonilla-Cárdenas A 2015, 'Características agronómicas, composición bromatológica, digestibilidad y consumo animal en cuatro especies de pastos de los generos Brachiaria Y Panicum', Tropical and Subtropical Agroecosystems, vol. 18, pp. 291-301.

Posada, SL, \& Noguera RR 2005, 'Técnica in vitro de producción de gases: Una herramienta para la evaluación de alimentos para rumiantes', Livestock Research for Rural Development, vol. 17, Art. 36.

Posada-Ochoa, SL, Ramírez-Agudelo, JF \& Rosero-Noguera, R 2014, 'Producción de metano y digestibilidad de mezclas de kikuyu (Pennisetum clandestinum - papa (Solanum tuberosum)', Agronomia Mesoamericana, vol. 25, núm. 1, pp. 141-150.

Ramírez, OR, Ramírez, LRG \& López GF 2002, 'Factores estructurales de la pared celular del forraje que afectan su digestibilidad', Ciencia UANL, vol. V, núm. 2, pp. 180-189.

Roman, PH 1981 'Potencial de producción de los bovinos en el trópico de México', Ciencia Veterinaria, vol. 3, pp. 393-491.
SAS 2011. SAS/STAT Software. Version 9.3. Cary, NC SAS, USA: Institute INC

Saminathan, M, CC Sieo, CMVL Wong \& Ho YW, 2015, 'Effects of condensed tannin fractions of different molecular weights from a Leucaena leucocephala hybrid on in vitro methane production and rumen fermentation', Journal of the Science of Food and Agriculture, vol. 95, pp. 2742-2749.

Sánchez, DE, Arreaza, LC \& Abadía B 2005, 'Estudio de la cinética de degradación in vitro de cuatro forrajeras tropicales y una leguminosa de clima templado', Revista Corpoica, vol. 6, núm. 1, pp. 58-68.

Sánchez-Santillán, P, Meneses-Mayo, M, Miranda-Romero, L, SantellanoEstrada E \&Alarcón-Zúñiga B 2015, 'Actividad fibrolítica y producción de gas por Pleurotus ostreatus-IE8 y Fomes fomentarius-EUM1 en bagazo de caña', Revista MVZ Córdoba, vol. 20, pp. 4907-4916.

Sánchez-Santillán, P \& Cobos-Peralta, MA 2016 'Producción in vitro de ácidos grasos volátiles de las bacterias celulolíticas reactivadas y bacterias ruminales totales en sustratos celulósicos', Agrociencia, vol. 50, núm. 5, pp. 565-674.

Sánchez-Santillán, P, Cobos-Peralta, MA, Hernández-Sánchez, D, Álvarado Iglesias, A, Espinosa-Victoria, D \& Herrera-Haro, JG 2016 'Uso de carbón activado para conservar bacterias celulolíticas liofilizadas', Agrociencia, vol. 50, núm. 5, pp.575-582.

Schofield, P \& Pell, AN 1995, 'Measurement and kinetic analysis of the neutral detergentsoluble carbohydrate fraction of legumes y grasses', Journal of Animal Science, vol. 73, no. 11, pp. 3455-3463.

Stolaroff, JK, DW Keit \& Lowr, GV 2008, 'Carbon dioxide capture from atmospheric air using sodium hydroxide spray', Environmental Science \& Technology, vol. 42, pp. 2728-2735.

Tiemann, TT, CE Lascano, M Kreuzer \& Hess, HD 2008, 'The ruminal degradability of fibre explains part of the low nutritional value and reduced methanogenesis in highly tanniniferous tropical legumes', Journal of the Science of Food and Agriculture, vol. 88, pp. 1794-1803. Torres-Salado, N, Sánchez-Santillán, P, Rojas-García, AR, Herrera-Pérez, J \& Hernández-Morales J 2018, 'Producción de gases efecto invernadero in vitro de leguminosas arbóreas del trópico seco mexicano', Archivos de Zootecnia, vol. 67, núm. 257, pp. 55-59.

Trujillo, Al, Marichal, MJ \& Carriquiry, M 2010 'Comparison of dry matter and neutral detergent fibre degradation of fibrous feedstuffs as determined with in situ and in vitro gravimetric procedures', Animal Feed Science and Technology, vol. 161, pp. 49-57.

Valenciaga, D \& Chongo B 2004, 'La pared celular. Influencia de su naturaleza en la degradación microbiana ruminal de los forrajes', Revista Cubana de Ciencia Agrícola, vol. 38, núm. 4, pp. 343-350.

Van Soest, PJ, JB Roberton \& Lewis, BA 1991, 'Methods for dietary fiber, neutral detergent fiber, and nonstarch polysaccharides in relation to animal nutrition', Journal of Dairy Science, vol. 74, núm 10, pp. 3583-3597.

Vargas, J, M Pabón \& Carulla, J 2014, 'Producción de metano in vitro en mezcla de gramíneas-leguminosas del trópico alto colombiano', Archivos de Zootecnia, vol. 63, núm. 243, pp: 397-407. 